\title{
Re-Entry to School, During the Pandemic Covid-19 and Psychosocial Interventions
}

\author{
T. Gkatsa* \\ Pedagogy Department of Primary School, University of Ioannina, Greece \\ *Corresponding Author: Dr. T. Gkatsa; tgkatsa@uoi.gr
}

\begin{abstract}
One and a half years after the outbreak of the Covid-19 pandemic crisis, students are returning to school. Schools do not have the experience of dealing with a pandemic, as there is no organized model for returning students to school after the crisis. The COVID-19 pandemic with stressful conditions threatens the emotional well-being, mental, physical health and behavior of children and adolescents. Long term, children and adolescents may develop Post-Traumatic Stress Disorder (PTSD). To deal with and prevent the adverse effects, are suggested the application of psychological interventions in school. In article search minimal re-entry interventions have been implemented. The re-entry interventions that identified present a variety of methodological tools and methods. Re-entry interventions focus on recovery, psychological strengthening, resilience. They are expected to contribute to the rehabilitation, prevention of mental and physical health difficulties, adjustment, the well-being and academic success.
\end{abstract}

Keywords: Re-entry, school, pandemic Covid-19, Psychosocial Intervention

\section{INTRODUCTION}

About half a year after the outbreak of the Covid-19 pandemic, the scientific discussion turns its attention to the multilevel negative effects on life, mental health, well-being, social relationships, behavior, which may threaten the normal development of children and adolescents. Indicatively, it is worth mentioning that the latest reviews on the effects of the Covid-19 pandemic refer a significant burden on mental health and wellbeing with symptoms of anxiety, depression, different levels of stress in children, adolescents [1], [2], [3], physical symptoms, insomnia and headaches [4]. Similarly affect parents and careers of children and adolescents [1], [5], [6], [7]. [8].

In addition, isolation, lack of social contact with peers, lack of social networking and loneliness threaten the mental well-being, psychosocial development and mental resilience of children and adolescents [7], [8], [9], [10].

\section{PSYCHOSOCIAL INTERVENTION, TRAUMA AND RESILIENCE}

In a pandemic, experts say that children and adolescents may have traumatic experiences. There is a discussion of three different types of trauma that can be associated with before, during and after a pandemic. The pandemic may cause new trauma to the most vulnerable children and adolescents who have previous difficulties - "primary trauma". In pandemic conditions, cases of domestic violence, physical or emotional abuse and sexual violence have been reported several times. This form is also referred to as "secondary" trauma (it is not the first result of the condition) [11]. The pandemic can also trigger in children and adolescents some older trauma from experiences of death, abuse and violence. In these cases, mental health professionals report that in these cases the manifestations are similar to others such as depression and Post Traumatic Stress Disorder (PTSD) [12].

A previous study of American families on the effects of H1N1 and SARS-Cov (Severe Acute Respiratory Syndrome Coronavirus) found that $30 \%$ of quarantined children developed symptoms of PTSD. This is followed by post-traumatic stress, which is experienced with symptoms of depression, anxiety and long term other adverse mental health effects [13]. There is a gender difference, the girls being twice as likely to develop PTSD symptoms [14]. PTSD affects brain development in childhood. In particular, it alters the cerebral circuits of the anterior lobe, which cause a threat response and impaired regulation of emotions [15]. 
This is because it has neuroanatomical and neurofunctional effects such as decreased tension in the hippocampus, increased response to the amygdala, decreased prefrontal conjugation in the amygdala in the process of growth [15], [16].

The pandemics and the stressors, environmental factors, are likely to increase vulnerability to mental health problems for children and adolescents. However, some protective factors could contribute to strengthen and resilience and they could increase the ability to adapt positively to stressful and adverse conditions [17].

The concept of "mental resilience" refers to the ability of an individual to overcome the chances of negative developmental process, to recover under the influence of a stressful or traumatic event and to adapt to the trajectory of the normal course of development. Recovery from threat and trauma is possible because it endures and copes with stress until it finally manages to live well [18], [19], [20], [21].

The view of Dvorsky, Breaux \& Becker, (2020) that ordinary processes are the ones that fuel mental resilience and not some rare and special qualities, this reminds us of the value of simple human, relational everyday life. Mental resilience stems from the magic of everyday human processes, in close relationships, in satisfactory caregivers, in effective school, in opportunities for success, in beliefs about oneself. As a whole, the above human processes promote self-regulated learning, problem solving, adaptive motivation, perseverance and hope. All previous adaptive systems involve promotional mechanisms of mental resilience [22].

Everyday life, relationships in the pandemic period are disrupted, however the same source of difficulties highlights new opportunities and challenges. Opportunities are for positive family and educational change, which promotes the positive development of children and adolescents. In particular, it is reported that family members in pandemic conditions (confinement and isolation at home), share more time with each other and therefore family ties become more cohesive. Also, distance education at home (home schooling) deserves to be maintained as a possibility of education in special conditions. It acted as a substitute for training and highlighted several positive elements in learning level, as it allows the student to focus on himself, his personal learning pace and to manage his time and interests flexibly. In addition, parental supervision during the distance learning process allows parents to perceive specific cognitive, emotional or behavioral needs. In addition, in some cases it empowers children, who experienced the school environment as hostile and stressful because they had a hard time getting there, such as in the case of victimization [16].

The other dimension presents the pandemic as a challenge and opportunity. It confronts us with taking responsibility and trying to transform it into a strength, enhancing the mental resilience of children and adolescents. While the stressful conditions of the pandemic are potentially traumatic conditions, when some children and adolescents manage to stress, then on a personal level the opportunity is provided for psychological recovery, strengthening and avoidance of the risk of post-traumatic stress / trauma [23]. The process of recovery through transformation enhances their mental resilience and sense of ability to cope with stress and adapt to new conditions. In this way mechanisms are developed to deal with future stressful situations [24],[16].

\section{RE-ENTRY TO SCHOOL DURING THE PANDEMIC COVID-19 AND PSYCHOSOCIAL INTERVENTIONS}

The development of such mechanisms can occur for children and adolescents only through psychological support and interventions. The findings of a review of research on psychosocial interventions for children and adolescents during the pandemic period indicate a large lack of psychosocial interventions for children during the COVID-19 pandemic period. Research protocols were reviewed in Canada, China, USA, Hungary and the United Kingdom until September 2020. Forth interventions addressed at ten-years-old or younger children and seven interventions addressed at adults, parents and caregivers. The second category refers to interventions on stress, depression, psychosocial well-being and the quality of relationships. The review support that in the long term, mental health interventions in children and adolescents will act as a protective factor for the prevention of mental health problems. Also, recommends that greater emphasis be placed on promoting mental health and the quality of child / adolescent relationships [25].

Also, another brief review of studies from January 1946 to March 2020 on the effects of social isolation and loneliness on the mental health of children and adolescents, during the Covid-19 pandemic, revealed 63 relevant studies, out of a total sample of 51,576 children/teenagers. According to the findings, children and adolescents living in conditions of social isolation and loneliness are more likely to experience higher rates of 
anxiety and depression. In fact, it is noted the longer the period of loneliness, the higher the risk. The review recommends timely interventions in children and adolescents, to prevent mental health difficulties [26].

Educational intervention programs implemented to promote life skills based on HIV / AIDS information were positively assessed in terms of students' knowledge of HIV / AIDS, self-awareness and life skills, even two years after the completion of the program. Indicatively, it is mentioned that the program included two phases, the research and the intervention phase. It was annual, with four hours per week and addressed at students 9-14 years [27].

Intervention programs after the pandemic crisis and after school lock-in are considered essential for the recovery, well-being and academic progress of students [28], [29]. The school is the appropriate environment in which these interventions can be implemented, because it is the only context in which we can meet all children and all adolescents.

There are not many studies that present implemented programs during the covid-19 pandemic crisis and the return of children to school after Lockdown [30], [31], [32], [33], [34], [35]. The aforementioned studies present educational interventions in the crisis and in the return to school after Lockdown and aim at mental resilience [26]. Resilience process involves motives negotiating, managing and adapting to stress and trauma.

Relevant, is mentioned below a program that was implemented in students 11-12 years old by a mental health educator. It aimed to improve mental resilience through training skills and coping strategies that help develop self-efficacy. The interview method and motivation were used. The results showed a three-point improvement in mental resilience [30].

Another study was carried out shortly after the pandemic broke out. It was addressed at adolescents with impaired resilience. Uses mindfulness training to increase adolescents' mental resilience. He finds that increasing emotional intelligence improves a person's mental resilience and mental resilience contributes to their development [31].

Another support intervention uses trauma information. It deals with what hurts but can also help. It is addressed at students, whose families face financial problems during the pandemic. The intervention primarily includes and informs about the trauma. The analysis of the content of the discussions highlighted physical, academic, socio-emotional challenges, hostile pedagogy, lack of socialization. Important discussion points for trauma were relationships, joint action, self-regulation, socio-emotional learning, isolation, and enhanced resilience [32]

Another program was implemented in China during the pandemic crisis. It concerned the education of adolescents by peers and lasted eight weeks. It was based on a specific model of intervention. Finally, the results showed that it can significantly reduce the level of anxiety and depression in adolescents and improve their sleep quality [33]].

Another intervention implemented immediately after the students returned to university after the Lockdown. The relationship between stress (after returning to university) and growth was initially investigated. The intervention program was then implemented using positive training methods. The results showed the development of cognitive reassessment (15\%), emotional processing (7\%) and the power to attend distance education (16\%). The conclusions of the project raised the question of finding a model positive education, that will develop skills of prosperity and development in times of crisis [34].

Another intervention program was implemented in Italy and includes an 8-week CrossFit fitness program. The study concludes that the program could positively affect the overall physical well-being of healthy adolescents and improve perceived emotional self-efficacy [35].

The school represents the ideal context in which children and adolescents could return to the educational routine to be trained through intervention programs and activities in the development of emotional and social skills and a set of well-being skills that promote resilience [36]. The development of resilience through interventions in the educational process has one major advantage. They do not focus on the individual response of each student to difficult emotions but guide the process in team intervention. In addition, students are given the opportunity to painlessly express difficult emotions and to release redemptively through processing activities. Therefore, team intervention reduces the possibilities of future manifestation of post-traumatic stress disorder (PTSD) [37]. 
Interventions aimed to tackling the crisis/convid-19 follow the general, literature guidelines for the crisis in the school environment [38], [39]. In particular, it is proposed:

A. Crisis intervention program, based on common principles and methods of crisis management in the educational environment. It fits any type of crisis that occurs internationally [39], [40].

B. Re-entry intervention program, aiming at a) the renegotiation of emotions, b) the "rediscovery" of personal relationships and c) the ability to be aware of effective ways to deal with problems. With these goals it is proposed to design programs suitable for each developmental stage and level of education.

Thematic axes suggested as useful for designing school re-entry intervention programs during the crisis / covid-19 are:

i) Facilitating discussions in the classroom on issues related to the events of the crisis. Narrative activities are suggested. Through storytelling and discussion, children and adolescents externalize, interpret in a personal way their traumatic experience and relax.

ii) feel free to express openly their feelings, possible ambiguity, confusion and uncertainty, which can then be meaningfully reflected. The key to success is in sharing the different ways of dealing that will be heard [41].

iii) Creating opportunities for reconnection with the social environment. Through joint and participatory activities, the school routine is re-established and students rediscover stability. They reconnect with their classmates and develop social skills.

iv) Their interest shifts from stressful events to awareness of coping strategies. Discussing and sharing coping strategies provides children and adolescents with the opportunity to develop coping strategies through awareness.

v) Presentation of facts and provision of services: It is important that the information referring to hygiene measures, transmission risks, ways of dealing with etc., come from official sources of information.

vi) Training and education of teachers [36].

The aforementioned curriculum was implemented in Italian schools. It is listed in the educational directory of the national ministry of education in Italy, under the name SOFIA (course id: 42851). The online digital platform (ebookscuola.com.) was the educational environment, in which the course circulated. The main points of the course were: 1) The Study of the book, which was accompanied by a guide. 2) The Work with a series of activities, different for primary and secondary education. 3) Form to be completed by the teacher. 4) The Successful final evaluation had a success rate of more than $60 \%$ [36].

In another country, Tunisia, a central protocol was implemented to combat the psychological crisis, caused by the COVID-19 pandemic. The program included a helpline, psychoeducation, through a network of therapeutic intervention, consisting of volunteer professionals in mental health, social work and students of the same specialties [42].

In addition, to school interventions, is proposed the application of the tested "Collaborative Model". It is a model of intervention with the main coordinator being the psychological services, to coordinate the interacting systems of the family, the school and the society in the direction of the collaborative effect. Attention is paid to the teacher's grief, the teacher-student relationship, peer relationships, parent-child grief, parent-child relationships, marital relationship, family system. The expected results concern the effective and sustainable development of children and adolescents [43]. The Collaborative model is proposed for the case for the treatment of post-traumatic discomfort in children and adolescents after the COVID-19 pandemic. Usually after a pandemic crisis, governments offer psychological services to relieve children and adolescents of anxiety. Sometimes some adolescents, even after the traumatic event, may experience grief due to the unsettled atmosphere at school and in the family. The collaborative model is suggested as a response in case of posttraumatic discomfort.

\section{CONCLUSIONS}

The stressful conditions of the pandemic, mental and physical health difficulties, social difficulties potentially cause mental trauma. The school, as a fixed frame of reference for all children and adolescents, is called upon to interpret the pandemic as a crisis and to transform stress and trauma into a factor of mental resilience [16]. Organized and special interventions at every school level are considered necessary for this purpose. The importance of the interventions is confirmed by the fact that children and adolescents during the pandemic 
period is in a state of threat and suspension of many functions. The limited number of re-entry interventions shows the need to deal more with this.

At a third level - after the end of the pandemic - there is a need for future research to assess the overall psychosocial cost of the covid-19 pandemic period in the development of children and adolescents. At this third level to discuss psychosocial interventions at school, after the final end of the pandemic covid-19.

\section{REFERENCES}

[1] American Psychiatry Association (2020). Psychology's Understanding of the Challenges Related to the covid-19 Global Pandemic in the United States.

[2] Zhou S.-. J., Zhang L.-. G., Wang L.-. L., Guo Z.-. C., Wang J.-. Q., Chen J.-. C., Liu M., Chen X., Chen J.-. X. Prevalence and socio-demographic correlates of psychological health problems in Chinese adolescents during the outbreak of COVID-19

Eur.ChildAdolesc. Psychiatry. 2020;(9212296) https://link.springer.com/article/10.1007/s00787-02001541-4

[3] Xie, X., Xue, Q., Zhou, Y., Zhu, K., Liu, Q., Zhang, J., \& Song, R. (2020). Mental health status among children in home confinement during the coronavirus disease 2019 outbreak in Hubei Province, China. JAMA pediatrics, 174(9), 898-900 doi: 10.1001 / jamapediatrics.2020.1619

[4] Liu S., Liu Y., Liu Y. Somatic symptoms and concern regarding COVID-19 among Chinese college and primary school students: a cross-sectional survey. Psychiatry Res. 2020;289(qc4, 7911385) [PMC free article] [PubMed] [Google Scholar] [Ref list]

[5] Yang, Y., Peng, F., Wang, R., Guan, K., Jiang, T., Xu, G., ... \& Chang, C. (2020). The deadly coronaviruses: The 2003 SARS pandemic and the 2020 novel coronavirus epidemic in China. Journal of autoimmunity, 109, 102434. https://doi.org/10.1016/j.jaut.2020.102434

[6] Vlachos, J., Hertegård, E., \& Svaleryd, H. B. (2021). The effects of school closures on SARS-CoV-2 among parents and teachers. Proceedings of the National Academy of Sciences, 118(9).

https://doi.org/10.1073/pnas.2020834118

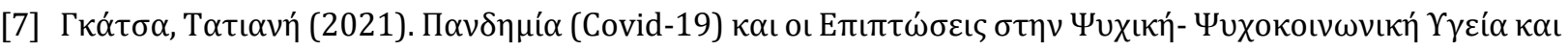

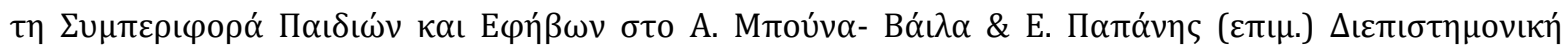

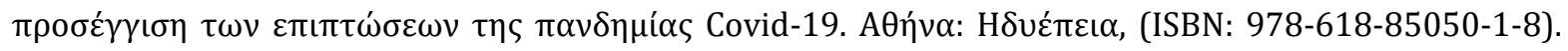
https://heyzine.com/flip-book/63cb13f1f3.html

[8] Gkatsa T. (2021). Mental Health and Behavior Difficulties for Children and Adolescents, during the COVID19 Pandemic Lockdown. International Journal of Scientific Advances.Special Issue: 2 | Sep 2021 Available Online: www.ijscia.com DOI: $10.51542 /$ ijscia.spi2.02

[9] Ghosh, R., Dubey, M. J., Chatterjee, S., \& Dubey, S. (2020). Impact of COVID-19 on children: special focus on the psychosocial aspect. Minerva Pediatrica, 72(3), 226-235. https://doi.org/10.23736/s00264946.20.05887-9.

[10] Giford-Smith ME, Brownell CA. Childhood peer relationships: social acceptance, friendships, and peer networks. J Sch Psychol. 2003;41(4):235-84. https://doi.org/10.1016/S0022-4405(03)00048-7

[11] Cohen, J. A., Jaycox, L. H., Walker, D. W., Mannarino, A. P., Langley, A. K., \& DuClos, J. L. (2009). Treating traumatized children after hurricane Katrina: Project Fleur-de Lis. Clinical Child and Family Psychological Review 12, 55-64. DOI 10.1007/s10567-009- 0039-2

[12] Grolnick, W. S., Schonfeld, D. J., Schreiber, M., Cohen, J., Vole, V., Jaycox, L., Lochman, J., Pfefferbaum, B., Wong, M., \& Zatzick, D. (2018). Improving adjustment and resilience in children following a disaster: Addressing research challenges. American Psychologist, 73(3), 215-229.

http://dx.dpo.org/10.1037/amp0000181 
[13] Kar, N., \& Bastia, B. K. (2006). Post-traumatic stress disorder, depression and generalised anxiety disorder in adolescents after a natural disaster: a study of comorbidity. Clinical Practice and Epidemiology in Mental Health, 2(1), 1-7.https://cpementalhealth.biomedcentral.com/articles/10.1186/1745-0179-2-17

[14] Garza, K., \& Jovanovic, T. (2017). Impact of gender on child and adolescent PTSD. Current psychiatry reports, 19(11), 1-6. https://link.springer.com/article/10.1007/s11920-017-0830-6

[15] Herringa, R. J. (2017). Trauma, PTSD, and the developing brain. Current Psychiatry Reports, 19(10), 1-9. https://link.springer.com/article/10.1007/s11920-017-0825-3

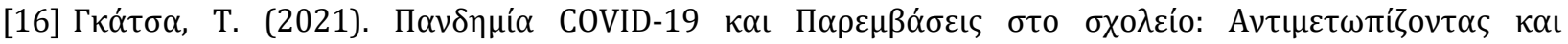

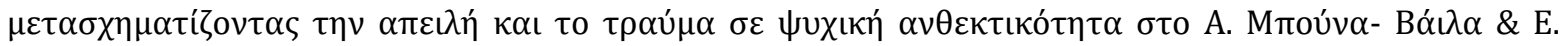

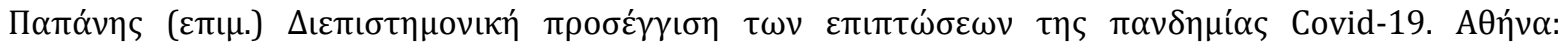

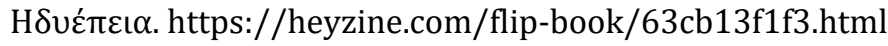

[17] Rosenberg, A. R. (2020). Cultivating deliberate resilience during the coronavirus disease 2019 pandemic. JAMA pediatrics, 174(9), 817-818.

[18] Masten, A. S., \& Barnes, A. J. (2018). Resilience in children: Developmental perspectives. Children, 5(7), 98113. https://doi.org/10.3390/children5070098

[19] Yoon, S. (2018). Fostering resilient development: protective factors underlying externalizing trajectories of maltreated children. Journal of Child and Family Studies, 27(2), 443-452. https://link.springer.com/article/10.1007/s10826-017-0904-4

[20] Titterton, M., \& Taylor, J. (2018). Rethinking risk and resilience in childhood and child maltreatment. British Journal of Social Work, 48(6), 1541-1558. https://doi.org/10.1093/bjsw/bcx117

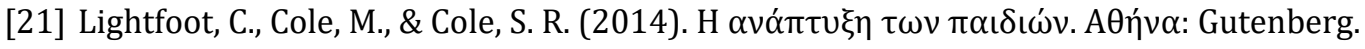

[22] Dvorsky, M. R., Breaux, R., \& Becker, S. P. (2020). Finding ordinary magic in extraordinary times: child and adolescent resilience during the COVID-19 pandemic. European child \& adolescent psychiatry, 1-3.

[23] APA (2020). Psychology's Understanding of the Challenges Related to the covid-19 Global Pandemic in the United States.

[24] Park, C. L. (1998). Stress-related growth and thriving through coping: The roles of personality and cognitive processes. Journal of social issues, 54(2), 267-277.

[25] Boldt, K., Coenen, M., Movsisyan, A., Voss, S., Rehfuess, E., Kunzler, A. M., ... \& Jung-Sievers, C. (2021). Interventions to Ameliorate the Psychosocial Effects of the COVID-19 Pandemic on Children-A Systematic Review. International journal of environmental research and public health, 18(5), 2361. https://doi.org/10.3390/ijerph18052361

[26] Loades, M. E., Chatburn, E., Higson-Sweeney, N., Reynolds, S., Shafran, R., Brigden, A., ... \& Crawley, E. (2020). Rapid systematic review: the impact of social isolation and loneliness on the mental health of children and adolescents in the context of COVID-19. Journal of the American Academy of Child \& Adolescent Psychiatry. https://doi.org/10.1016/j.jaac.2020.05.009

[27] Wei, L. I. A. O., Jiang, J. M., Bin, Y. A. N. G., Xin, Z. E. N. G., \& Su-Su, L. I. A. O. (2010). A life-skills-based HIV/AIDS prevention education for rural students of primary schools in China: what changed? What have we learned? Biomedical and Environmental Sciences, 23(5), 409-419. https://doi.org/10.1016/S08953988(10)60083-9

[28] Hatzichristiou, C., Issari, P., Lykitsakou, K., Lampropoulou, A., \& Dimitropoulou, P. (2011). The development of a multi-level model for crisis preparedness and intervention in the Greek educational system. School psychology international, 32(5), 464-483.

https://doi.org/10.1177\%2F0143034311402918 
[29] Pahl, A. L. (2020). Re-Entering schools after the pandemic: An analysis of helping children after a disaster. The Interactive Journal of Global Leadership and Learning, 1(2), 7. https://red.mnstate.edu/ijgll/vol1/iss2/7

[30] Lee, J. A., Heberlein, E., Pyle, E., Caughlan, T., Rahaman, D., Sabin, M., \& Kaar, J. L. (2021). Evaluation of a resiliency focused health coaching intervention for middle school students: Building resilience for healthy kids' program. American Journal of Health Promotion, 35(3), 344-351. https://doi.org/10.1177\%2F0890117120959152

[31] Yuan, Y. (2021). Mindfulness training on the resilience of adolescents under the COVID-19 epidemic: A latent growth curve analysis. Personality and Individual Differences, 172, 110560.

https://doi.org/10.1016/j.paid.2020.110560

[32] Giboney Wall, C. R. (2021). What Hurt and What Helped: How One School's Trauma-Informed Approach Provided Support During the Pandemic. Journal of Loss and Trauma, 1-14. https://doi.org/10.1080/15325024.2021.1943127

[33] Ding, X., Yao, J.(2021). Peer education intervention on adolescents' anxiety, depression, and sleep disorder during the covid-19 pandemic https://doi.org/10.24869/psyd.2020.527

[34] Waters, L., Allen, K. A., \& Arslan, G. (2021). Stress-related growth in adolescents returning to school after Covid-19 school closure. Frontiers in Psychology, 12. https://dx.doi.org/10.3389\%2Ffpsyg.2021.643443

[35] Cataldi, S., Francavilla, V.C., Bonavolontà, V., (...), Latino, F., Fischetti, F. Proposal for a fitness program in the school setting during the covid 19 pandemic: Effects of an 8-week crossfit program on psychophysical well-being in healthy adolescents https://dx.doi.org/10.3389\%2Ffpsyg.2021.643443

[36] Capurso, M., Dennis, J. L., Salmi, L. P., Parrino, C., \& Mazzeschi, C. (2020). Empowering children through school re-entry activities after the COVID-19 pandemic. Continuity in Education, 1(1). https://continuityineducation.org/articles/10.5334/cie.17/

[37] Tol, W. A., Komproe, I. H., Susanty, D., Jordans, M. J. D., Macy, R. D., \& De Jong, J. T. V. M. (2008). Schoolbased mental health intervention for children affected by political violence in Indonesia: A cluster randomized trial. JAMA, 300(6), 655-662. https://doi.org/10.1001/jama.300.6.655

[38] Sandoval, J. (2013). Crisis Counseling, intervention and prevention in the schools. New York, NY, USA: Routledge. DOI: https://doi.org/10.4324/9780203145852

[39] Jimerson, S. R., Brock, S. E., \& Pletcher, S. W. (2005). An integrated model of school crisis preparedness and intervention: A shared foundation to facilitate international crisis intervention. School Psychology International, 26(3), 275-296. https://doi.org/10.1177/0143034305055974

[40] Titterton, M., \& Taylor, J. (2018). Rethinking risk and resilience in childhood and child maltreatment. British Journal of Social Work, 48(6), 1541-1558. https://doi.org/10.1093/bjsw/bcx117

[41] Brock, S. E., \& Jimerson, S. R. (2004). School crisis interventions: Strategies for addressing the consequences of crisis events. In E. R. Gerler, Jr. (Ed.), Handbook of school violence (pp. 285-332). https://doi.org/10.1177\%2F0143034305055974

[42] Zgueb, Y., Bourgou, S., Neffeti, A., Amamou, B., Masmoudi, J., Chebbi, H., ... \& Bouasker, A. (2020). Psychological crisis intervention response to the COVID 19 pandemic: A Tunisian centralised Protocol. Psychiatry research, 289, 113042. https://doi.org/10.1016/j.psychres.2020.113042

[43] Zhou, M., Zhang, X., \& Qu, J. (2020). Coronavirus disease 2019 (COVID-19): a clinical update. Frontiers of medicine, 14(2), 126-135. https://link.springer.com/article/10.1007/s11684-020-0767-8 